\title{
Editorial
}

\section{Looking for a Sign}

So, this November editorial marks the end (or not even the end) of another year of chaos and loss, unrelenting change, and ambiguity.

It has been a struggle, in some ways, more than the previous year. We have had to deal with the pandemic numbers climbing, the indecisive leadership, the loss of colleagues and family members, the loss of jobs, more work and more barriers to getting that work done, stress and incivility, and on and on. Colleagues have experienced fear for their children. There are children (and adults) who are afraid to go out in public, afraid they may contract the virus or pass it on with disastrous results. Colleagues are experiencing combative students in the classroom who call them out for wearing a mask. Through it all is the uncertainty-of the future, the economy, having a job (still! Not just due to COVID but to changes in leadership and to political maneuvering).

It sometimes gets to be too much.

Then I saw a sign.

Literally.

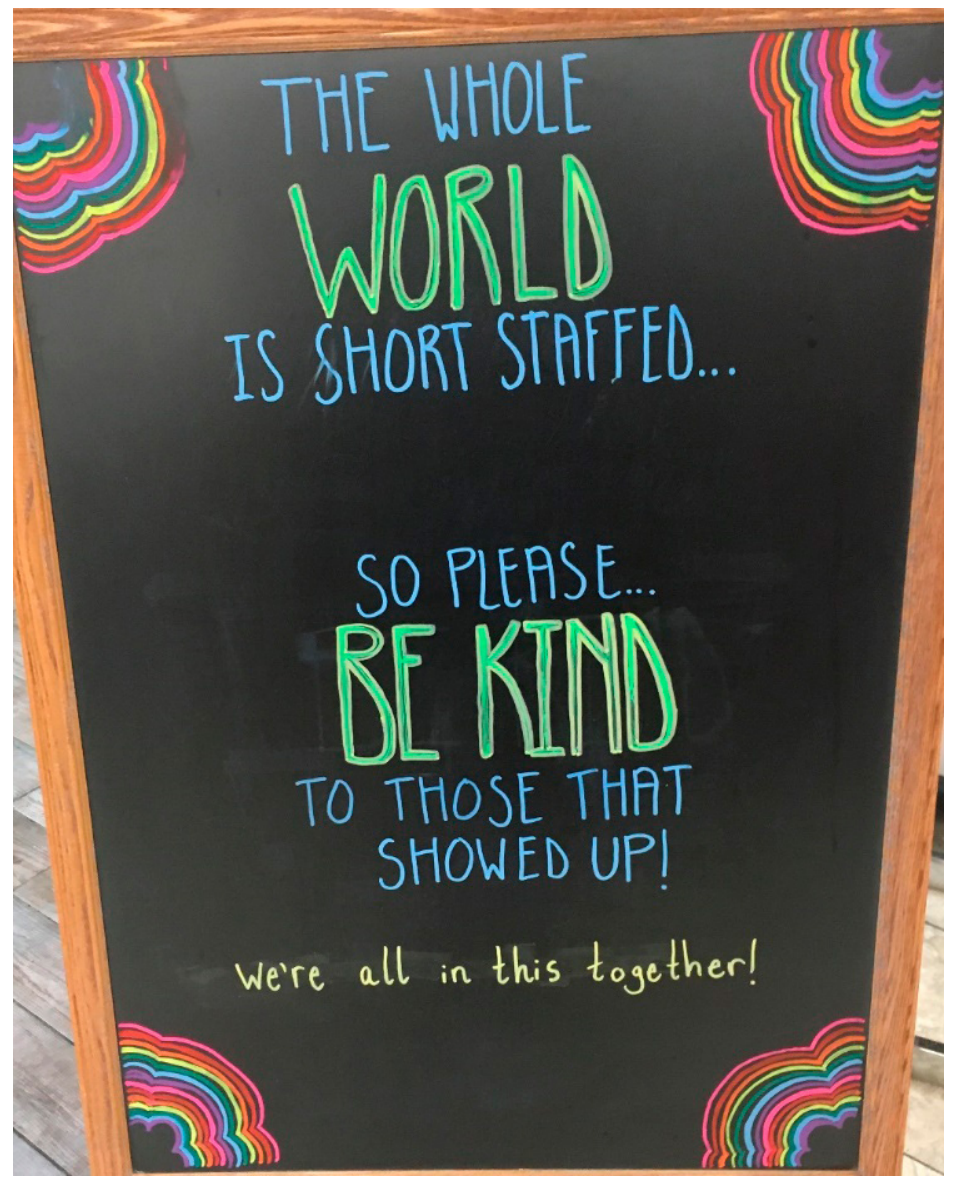

I guess I was looking for one (although, really, I was looking for caffeine). It seems like we all feel this sentiment-in some cases literally, as libraries change hours or put out apology signs when $20 \%$ of their staff is out. As low-key and trivial as this sign might seem, it really came at the most opportune time, reminding me that we are not alone, that everyone is experiencing these hard times and that this is the time to be patient, flexible, and kind - with others and with ourselves.

\section{Be Patient and Be Flexible}

This has been the litany for the past 2 years. It is advice I give my students and staff as we go into each new term and the anxiety of patrons ramps up. It takes a lot of energy to maneuver through this environment-seeming to move from one crisis to another and provide information, assistance (solace, a refuge, a sounding board, etc.) for everyone who needs it. 


\section{Be Good to Yourself}

I may have mentioned previously that, whenever I fly, there is a useful reality check that is not actually what was intended. The very mundane (and often annoying) spiel that the flight attendant does (and that almost everyone ignores) is a bit of a wake-up call that can apply to so many situations - and certainly to the life we are currently experiencing: "In the event of an emergency, oxygen masks will descend from the ceiling. Put your own mask on first and then assist anyone else." It could be argued (and has certainly prompted lots of conflict) that the pandemic is an emergency-and in spite of the fact that everyone is suffering and needs help in some way, it is important to take care of yourself first.

It is impossible to take care of your kids, partner, parents, coworkers, patrons, or community if you don't have the peace of mind and the energy to sustain yourself. Librarians, as a profession, are particularly at risk-so much of what drew us (me) to the profession was to serve and help. Several recent articles have addressed this issue, even in terms of the pandemic-vocational awe is real and, in some situations, we do ourselves a great disservice personally and professionally. It is also reinforced by our leadership (who may recognize it as a motivating factor, even when it may be detrimental to our wellbeing). For instance, when a library director tries to get people fired up by acknowledging that (and I paraphrase here), "yes, it's been tough and if you need to talk to someone or get help, there are people for that, but we should do what we do best and focus on work," they aren't exactly looking out for your best interests. I do realize that not all library administrators use this cardboard motivation to trade on their employees' desire to help and be of service to the detriment of their mental health (just as not all states have a ban on mask and vaccine mandates), but this is but an example of what some are dealing with.

Vocational awe is not the only factor for academic librarians - academic guilt and worklife imbalance are ever present-soaking up any peace of mind and any time for self-reflection and self-rejuvenation. But, thinking back to the "in case of emergency, take care of yourself first" directive-consider how to simplify your life (at work or at home-or both), how to remove some of the stress and anxiety, and how to find a place (or head space) that brings peace.

\section{Be Focused on What is Important (to You)}

This is easier to say than to do-so many of us do not have the agency and have too many commitments to really feel like we can let certain things go and focus on what is important to us. Yes, there are tradeoffs and consequences - and sometimes the decisions are hard and sometimes that may mean a lot of change and possibly giving something up. That is a decision that everyone needs to consider for their own situation.

Yes, we are all less productive than we were-it is easy to take responsibility (i.e., blame) for that-but the reality is that there are more processes, more barriers, more considerations in play than there once were. We are doing the functions we had when things were "normal" (pre-COVID), we are "pivoting" (to use a buzzword) to address the ever-present changes and ever-changing demands in higher education, and we are doing dual processing (e.g., teaching in person and online synchronously) to try and meet every eventuality. Even doing the same job comes with additional systems and approvals to navigate - and small deviations seem to prompt memos in triplicate up the reporting line. 
A recent column in the Chronicle of Higher Education (which I seem to read habitually these days as it acknowledges that academe is insane, which is weirdly reassuring to me right now) struck a chord. A long-time contributor gave a candid and pragmatic narrative about why he has chosen to leave the academy. His is a thoughtful approach, taking into account both the current climate and the shift in his professional goals. It echoes a lot of my own thoughtsdisconcertingly so in some aspects (re: social media, academic freedom, and growing stale).

So, I admit it-I have also been looking at other (not just library) job postings, articles and blogs on burnout and librarians changing careers. I have, like so many others, been adding up my days until retirement and trying to figure out how long I can hang in there (and whether I should). I am disillusioned with the leadership and lately frustrated and annoyed with those who seem to have taken my efforts and commitment for granted (thereby diminishing that commitment). I share this not to complain (or not solely to complain, anyway) but also because I know others have these feelings which may make them feel alone and less than. It has been hard to be positive in the face of it all-but the reminder that we are all in the same boat and there are things that we can do to lessen people's (and our own) load is helpful to get focused on engaging constructively.

That said, it's okay to say no and be upfront about your level of commitment and your capacity. This is something that we are loathe to do (see above about vocational awe and academic guilt)-especially as we fear it may impact how we are evaluated or any future professional opportunities. And it may. But an honest answer is a gift-and knowing where you stand in an organization is valuable information as well.

It's also okay to ask for help-which none of us wants to do, as it too seems to send a signal that we can't do our jobs. However, organizations will take as much of your time, effort, commitment as you will give them. Maintaining a worklife balance is not on the organization; it is on you, the individual. Deciding what is important and making tradeoffs is part of it.

\section{Be Kind and Be Thankful}

It is funny how many times I hear (or say) "Let me know if I can help" - a nice but noncommittal way to express support. The pandemic has brought home to me how unhelpful that actually is (although it does still creep into my emails) so I have also shifted my thinking to offer more concrete help that fits the situation: "can I take on some of the duties of committee secretary to lighten your load", "can I help you create the libguide for this class", "can I cover for you while you are a conference", etc. They are small tasks-but I have come to realize that every effort helps and the sentiment is more meaningful when it is backed with something more tangible. Even something as small as that sign can lift someone up (as it I did for me) but even the thought, when personal, counts.

What also counts is thanks. I am not much for holidays - but I always like that there is a time to stop and reflect and gives thanks (and I completely acknowledge that the actual commemoration of Thanksgiving is fraught with controversy and contradiction). However, the reminder to be thankful, to not take anyone or any kindness for granted and to give back, is valuable in itself. This is especially important for a journal whose existence is dependent on authors who devote their time to research and writing and to the reviewers who devote their efforts and expertise to assessing and providing feedback for those papers as well as all the others.

There are so many who have given of their time and attention- even in the midst of this pandemic when everything seems to take so much more effort. At the risk of sounding like 
an academy award winner, there are a number of people who have made the journal successful, even throughout the pandemic, political turmoil, economic downturns (with job loss and furloughs) and everything else:

The editorial team has been there through thick and thin:

Ellen Filgo as social media editor, managing the dialogues that the journal prompts and employing technology to give voice to the journal;

Emily Drabinksi who has expanded the content and participants in the book review to be more inclusive and strategic;

Stephanie Davis-Kahl and Eric Johnson, who are the unsung editorial assistants, helping manage the volume of submissions in a timely way.

Editor-designate Kristen Totleben has jumped right in and will bring fortitude and a fresh perspective to the journal.

The ACRL and production staff without whom there would be nothing to read: Dawn, Tim and David are superlative and keep the journal (and me) on track! They are the one constant in an era of change.

The editorial has been the best I have worked with, representing the journal and identifying opportunities for engagement, helping shape the direction with new policies and practices and providing constructive feedback:

Dr. Jason K. Alston
Christopher Cox
Michelle Demeter
Dr. Sarah Rose Fitzgerald
Adrian K. Ho
Lizah Ismail
Sarah Kostelecky

Dr. Megan Jane Oakleaf Ms. Erin Elizabeth Owens Ms. Nicole Pagowsky Anthony Stamatoplos Eamon C. Tewell Minglu Wang Brad L. Warren
David Free Jennifer A. Maddox Abbott Dr. Robert Jay Malone Dr. Jon E. Cawthorne, Ph.D. Dr. John Budd Penny Beile

The article peer reviewers are the engine of the journal, bring their expertise and experience to help frame the scope to align with emerging trends and identify best practices:

Melissa Adler

Noa Aharony

Frank R. Allen

Melissa Becher

Rickey D. Best

Kelly Diane Blessinger

Dr. Colleen Boff

Tim Bottorff

Joe C Clark

Christopher Cox

Ilka Noel Datig

Jeanne Davidson

Lisa DeLuca

Michelle Demeter

Paula R. Dempsey

Shevon Desai

marta deyrup
Jennifer Doty

David Dowell

Dr. Kathy Brock Enger

Dr. Jody Condit Fagan

Louise Mort Feldmann

Dustin Fife

Dr. Sarah Rose Fitzgerald

Mary Francis

Jan Fransen

Megan Gaffney

Julie Gilbert

Don Gilstrap

Rumi Graham

Melanie Griffin

Dr. Melissa Gross

Jim Fabian Hahn

Nathan Hall
Mr. Kevin S. Hawkins

Merinda Kaye Hensley

Bruce Herbert

Dr. Melody Herr

Alison Hicks

Lisa Hinchliffe

Adrian K. Ho

Sheril Hook

Soo-yeon Hwang

Sharon Ince

Ashley Ireland

Lizah Ismail

Trudi Jacobson

Maria Anna Jankowska

Sigrid Kelsey

Mr. Steven A. Knowlton

Sarah R Kostelecky 
Don Latham

Deborah Lee

Dr. Joan K. Lippincott

Emmett Lombard

Jennifer Maddox Abbott

Jack Maness

Janie Mathews

Ms. Bethany Sheriese Mc-

Gowan

Gail McMillan

Nan McMurry

James Morris-Knower

Sarah Murphy

Rajiv Nariani

David S. Nolen
Megan Oakleaf

Manuel Ostos

Erin Elizabeth Owens

Nicole Pagowsky

Anali Maughan Perry

Tara Marie Radniecki

Dr. Thomas L. Reinsfelder

Dr. Karen Schmidt

Greg Seppi

Danielle Skaggs

Jordan Sly

Julie M Still

Sean Stone

Eamon C. Tewell

Joel Thornton
David C. Tyler

Wyoma vanDuinkerken

Minglu Wang

Brad Warren

Andrew Wesolek

Lindsey Wharton

Michael Whitchurch

Stephen Wiberley

Virginia Kay Williams

Zhihong $\mathrm{Xu}$

Le Yang

Holt Zaugg

Li Zhang

Yin Zhang

The book reviewers, who under Emily Drabinski's direction, are transforming the scope of those publications relevant and significant to the profession and bringing broader perspectives:

Nora Almeida

Jason Alston

Meaghan Alston

Giovanna Badia

Nimisha Bhat

Jennifer Brown

Richelle Brown

Robin E. Brown

Iyra S. Buenrostro

Melissa Chomintra

Jasmine Clark

Lorna M. Dawes

Jeffrey Delgado
Diane Dias De Fazio

Megan Duffy

Jason Dyck

Shanti Freundlich

Scarlet Galvan

Jordan Hale

Twanna Hodge

Kathia Ibacache

Natasha Jenkins

Hannah Scates Kettler

Chelsea Largent

Danya Leebaw

Joshua Neds-Fox
Annie Pho

Nandi Prince

Debbie Rabina

Shannon K. Supple

Jaime Taylor

Eamon C. Tewell

Max Thorn

Carrie Wade

Amy Wickner

Alexandra Wieland

Ginger H. Williams

We also want to acknowledge the authors who work hard to stay current and add to scholarship and practice-and who have been so patient as various issues have made the review process a little more protracted lately. We really appreciate all their efforts to provide rigorous, well-written papers to share with their peers-contributing their experience and being open to feedback.

And, finally, to our readers and the scholars and practitioners in the profession more broadly, who also help shape the direction of the journal and are so willing to give feedback and contribute to the dialogue. My hope that is that journal does, in at least a small way, contribute to your professional life and your work.

\section{Be Well}

